\title{
Design e Marketing Estratégico: integração e aplicação prática no composto mercadológico
}

\author{
Design and Strategic Marketing: integration and practical application \\ in the marketing mix
}

\author{
Torres, Pablo Marcel de Arruda; Mestre; \\ Universidade Federal de Campina Grande - UFCG \\ pablo.marcel@gmail.com \\ Dantas, Laíla Alves Marinho; Graduanda; \\ Universidade Federal de Campina Grande - UFCG \\ laila_amd@hotmail.com
}

\begin{abstract}
RESUMO
O trabalho objetiva demonstrar através de um estudo de caso como as relações entre design e marketing podem ser estreitadas a fim de gerar valor em todo composto mercadológico, criando novas experiências para uma marca de batom. A base de informações foi uma Pesquisa de Mercado cujos resultados foram aplicados na definição de estratégias de marketing e determinaram a forma como o design foi elaborado. O resultado é um projeto completo de design, que envolveu desde o Produto até a comunicação da marca.
\end{abstract}

Palavras-chave: Pesquisa de Mercado; Design Estratégico; Composto Mercadológico; Comunicação Corporativa

\begin{abstract}
This paper aims to demonstrate through a case study how the relationship between design and marketing can be narrowed in order to generate value throughout the marketing mix, creating new experiences for a lipstick brand. The information base was a market research and the results were applied in marketing strategies and determined how the design was developed. The result is a complete project design, which involved from product to brand communication.
\end{abstract}

Keywords: Marketing Research; Strategic Design; Marketing Mix; Corporate communication

\section{Introdução}

O design é tido como uma força integradora entre todas as ferramentas da empresa, devendo trabalhar próximo principalmente da área de marketing, em contato com os clientes, propondo assim uma estrutura de ação estratégica do design (GILLESPIE, 2002). Neste tipo de abordagem, os projetos de design são concebidos e focam na identificação e criação de condições para que ferramentas de design possam ser propostas e promovidas (BEST, 2006 apud DEMARCHI, FORNASIER e MARTINS, 2011). Torna-se fundamental a identificação de oportunidades que facilitem ao designer entender o público-alvo e o mercado, interpretar o consumidor e suas necessidades, e propor estratégias que deem suporte para a realização e comunicação das metas da organização (DEMARCHI, FORNASIER e MARTINS, 2011).

A Pesquisa de Mercado como ferramenta de Marketing aliada ao Design pode resultar em estratégias adequadas para o desenvolvimento de marcas fortes, diferenciadas e de maior valor 
percebido pelos clientes. $O$ design enriquece a pesquisa de marketing, fornecendo uma nova forma de segmentar o mercado pela percepção estética do consumidor e oferecendo modelos para analisar atributos de produtos com atributos de design (BORJA DE MOZOTA, 2011). A Pesquisa de Marketing consiste em projetos formais que visam à obtenção de dados de forma empírica, sistemática e objetiva para a solução de problemas ou oportunidades específicas relacionadas ao marketing de produtos e de serviços. É utilizada para identificar preferências, hábitos e costumes, perfil socioeconômico, imagem de marca, intenções de compra e análise de participação de mercado, entre outras. Incluem-se aqui também os estudos de previsão de demanda e de potencial de mercado, tendências de negócios e pesquisa de imagem corporativa (SAMARA e BARROS, 2007). O uso mais amplo e sistemático da pesquisa de mercado no Brasil, a partir dos anos 60, possibilitou as primeiras informações de como as marcas são percebidas e reconhecidas pelos consumidores (PINHO, 1996).

As estratégias de marketing resultam em um mix de ferramentas que orientam as empresas para uma visão de realidade do mercado que são imprescindíveis para o trabalho do designer. KOTLER e KELLER (2006) definem composto de marketing (ou Marketing Mix) como o conjunto de ferramentas de marketing que a empresa utiliza para atingir seus objetivos no mercado-alvo. $O$ composto mercadológico conterá as decisões a serem tomadas para que se exerça influência sobre os canais comerciais e os consumidores finais. Essas ferramentas se dividem em grupos de estratégias conhecidas como os 4Ps (Produto, Preço, Ponto de venda, Promoção). Logo, quanto mais clara é a visão mercadológica de uma empresa, melhores serão seus produtos e serviços, pois serão baseados em projetos sólidos e desenvolvimento estruturado (ACAR FILHO, 1997). Reforçando esta ideia, MAGALHÃES (1997) destaca que a abordagem estratégica materializa-se quando o importante é desenvolver o design certo (eficácia do design) e não somente desenvolver corretamente o design (eficiência no processo de design).

Segundo BORJA DE MOZOTA (2002), o lançamento de uma marca pode ser considerado um dos modos mais eficientes de difundir o design no âmbito corporativo, sendo a primeira razão para integração do design em uma empresa. Neste momento, o design se amplia e passa a ter a importância estratégica de apresentar a empresa ao mercado, posicionando-a na sociedade e dando forma à sua própria estratégia. $O$ designer é provocado a conceber produto, comunicação e distribuição, que passam a ter o mesmo peso e importância, ampliando o projeto de design com conceitos inerentes ao marketing e às questões mercadológicas, bem como àqueles relativos à publicidade, estratégia de mercado, relações públicas, promocionais e de comunicação (DE MORAES, 2010).

Ainda dentro deste espectro estratégico, DICKINSON e SVENSEN (2000) afirmam que os clientes querem experimentar sensações de prazer de estilo e beleza das empresas com as quais eles resolveram se relacionar. A estética atraente terá impacto na avaliação do produto, acrescentada a preço, marca e desempenho, sendo item fundamental na competição industrial (YAMAMOTO e LAMBERT, 1994), sobretudo em um mercado voltado para o público feminino. No que tange esse aspecto, LÖBACH (2001) ressalta que a estética empírica faz pesquisa das ideias sobre os valores estéticos das pessoas, contribuindo ao processo de design com as preferências do usuário. Os resultados deste estudo devem ser utilizados durante o projeto como valores prescritos, sendo um dos fatores determinantes na configuração do produto.

O trabalho foi desenvolvido seguindo as etapas de planejamento e execução de uma pesquisa de mercado e conhecimento dos interesses e hábitos do público-alvo para posterior desenvolvimento do composto mercadológico da nova marca, permeando todas as estratégias de marketing com a utilização do design, que vão desde o desenvolvimento de produto até as táticas de distribuição, preço e comunicação. Propõe também evidenciar a importância do conhecimento profundo do público-alvo a que o produto é destinado bem como das técnicas de pesquisa e aplicação dos resultados em todos os elementos de design que compõem o marketing mix. Vale também ressaltar que o caso aqui descrito tratou-se de trabalho desenvolvido em âmbito acadêmico, o que caracteriza o estudo de caso aqui descrito como fictício, explicitando a aplicação prática das atividades de planejamento das estratégias de marketing e concepção de design em todos os níveis do composto mercadológico. 


\section{Definição do Público-Alvo}

A análise do perfil do consumidor, de seu comportamento de compra, da concorrência e de sua evolução, dos produtos e das práticas de marketing vigentes determinam as ações para planejamento do composto de marketing de uma marca (SAMARA e BARROS, 2007).

O público-alvo escolhido para desenvolvimento do produto são mulheres de 20 a 24 anos, brasileiras de classe social média e que possuem curso superior completo ou em andamento. Solteiras, elas costumam utilizar o batom tanto no dia-a-dia como para sair à noite. Preocupam-se com a aparência, são vaidosas e procuram estar sempre belas e bem vestidas. A maioria não possui condições de obter aquilo que realmente deseja, como produtos caros e de marca conhecida, porém procuram alternativas semelhantes e acessíveis à sua realidade financeira.

\section{Pesquisa de Mercado}

A pesquisa de produto procura identificar quais os diferenciais competitivos entre produtos concorrentes, assim como a aceitação e o potencial para novos produtos, ou modificações naqueles já existentes. Esse tipo de pesquisa também proporciona testes de produto e determinação de preços, além de colher opinião sobre todas as suas características, como qualidade, cor, marca, design e conceito de produto, entre outros itens que podem ser verificados (SAMARA e BARROS, 2007).

Os objetivos da pesquisa foram identificar as preferências das potenciais consumidoras a respeito de atributos relevantes ao mercado de batons, como cor, acabamento, material, funcionalidade e marca, bem como hábitos de consumo e de usabilidade, a influência da marca e fatores que influenciam e estimulam a compra do produto, bem como os meios de propaganda utilizados.

Para realização da Pesquisa de Mercado foram utilizadas 12 amostras de batons de marcas comercializadas e presentes no mercado, numeradas de 1 a 12 para não tornar público seus nomes reais (Figura 1). Foram entrevistadas 20 estudantes, na faixa etária de 20 a 24 anos, que possuem o hábito de comprar e utilizar com frequência esse produto e coerentes com o perfil pré-definido do público em potencial.

Como instrumento da pesquisa, foi elaborado um questionário como roteiro para uma entrevista. Foram elaboradas vinte e quatro questões, subjetivas e objetivas, que geraram dados quantitativos, apesar de dados qualitativos serem levados em consideração nas questões subjetivas. As questões foram agrupadas de acordo com grupos de interesse, como forma, cor, material, acabamento, acessórios, usabilidade e marca. De acordo com SAMARA e BARROS (2007), a pesquisa quantitativa refere-se a uma análise numérica das relações de consumo. Esses estudos são realizados a partir da elaboração de amostras da população, utilizando-se a estatística para extrapolar os resultados obtidos na amostra em estudo para determinada população. Os resultados da pesquisa foram analisados e interpretados a partir de médias e percentuais das respostas obtidas.

Para avaliação e análise dos batons por parte das possíveis usuárias foi realizado um teste pareado, comparando-os entre si, de acordo com cada questão abordada. O teste pareado faz uma avaliação comparativa entre produtos por parte do consumidor, sendo utilizado quando se deseja conhecer os atributos valorizados entre produtos concorrentes e quando se deseja avaliar a preferência por versões/modelos (SAMARA e BARROS, 2007). Assim, as doze amostras de batons foram dispostas para análise das entrevistadas, para que pudessem manuseá-las e analisá-las melhor.

Nas questões de forma o objetivo foi observar quais são àquelas mais atraentes dentre as existentes nas amostras escolhidas, de acordo com as entrevistadas: se eram formas cilíndricas e orgânicas ou formas retas e quadradas. Nas questões referentes à cor a intenção foi observar se as entrevistadas preferiam embalagens mais sóbrias e neutras ou mais coloridas e chamativas. Quanto ao material e acabamento, a intenção foi descobrir se havia alguma preferência entre embalagens foscas ou brilhosas, douradas ou prateadas, transparentes ou opacas e principalmente se estas questões eram relevantes no momento de compra. Questões acerca de acessórios foram elaboradas para descobrir se os espelhos acoplados a determinadas embalagens fazem diferença ou são relevantes como estímulo à compra. As questões de usabilidade procuravam induzir respostas acerca de como a usuária observava a cor do batom e como ela preferia que ela fosse representada em sua embalagem. 
Design e Marketing Estratégico: integração e aplicação prática no composto mercadológico

Também foram indagadas acerca de onde costumam guardar esse produto: se em casa ou carregam na bolsa, por exemplo. As questões sobre marca procuraram identificar se a mesma influenciava no processo de compra e se sobressaía em relação a outros aspectos do produto.

Figura 1 - Amostras de embalagens de batons

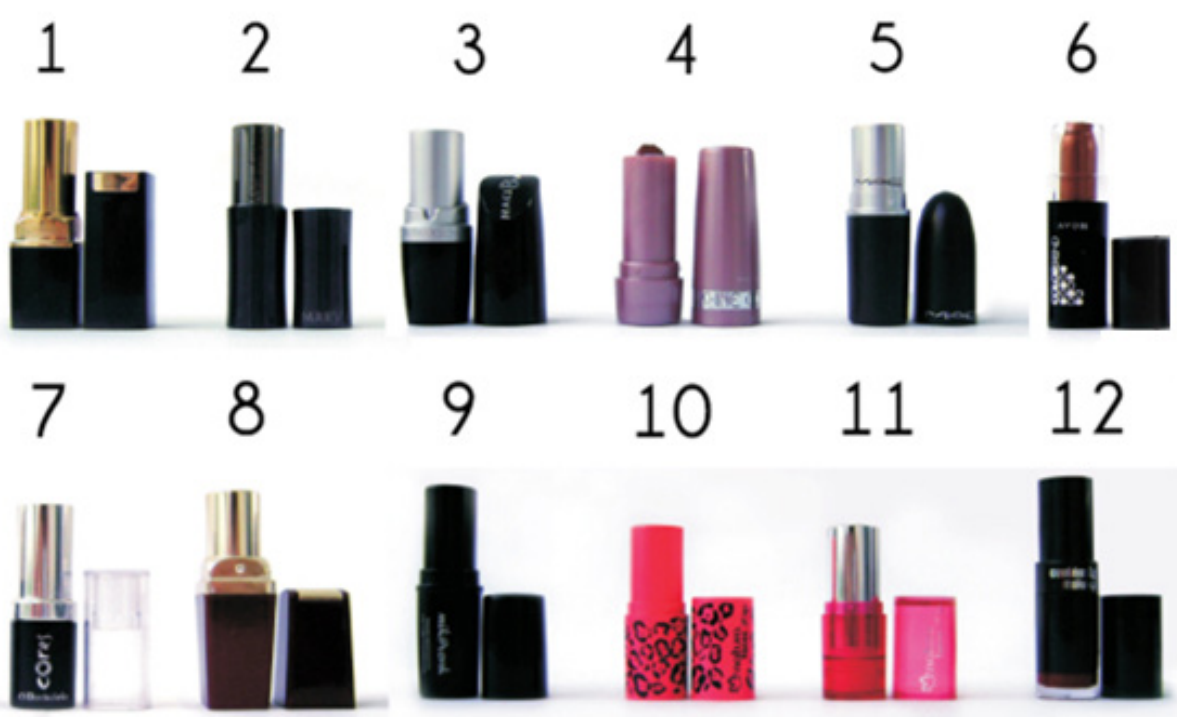

Identificou-se, acerca das perguntas sobre forma, que $75 \%$ das entrevistadas preferiram embalagens cilíndricas e arredondadas. Em se tratando de cores, $60 \%$ das usuárias preferiram cores discretas, como o preto, para embalagens discretas. Para embalagens coloridas, $80 \%$ das entrevistadas deram preferência a cores fortes e vibrantes.

Em se tratando de questões referentes ao acabamento da embalagem, a cor dourada e acabamento fosco também foram elementos preferenciais, conquistando $55 \%$ das entrevistadas. A grande maioria das entrevistadas (70\%) opinou que o acabamento metálico transmite luxo e sofisticação, na qual $62 \%$ apresentaram preferência também por metálicas prateadas e foscas. Segundo $85 \%$ delas, embalagens são mais bonitas quando possuem uma combinação de acabamentos.

Dentre as entrevistadas, $45 \%$ acham que acessórios como espelhos são irrelevantes na embalagem e a grande maioria (95\%) descobre a cor do batom abrindo-o, ao invés de fazê-lo através de adesivos ou outros artifícios.

Mais da metade das entrevistadas afirmou comprar o batom levando em consideração a sua cor, ou seja, o atributo estético do batom é predominantemente mais forte do que seu atributo funcional. Porém, as entrevistadas também mostraram que gostam da marca estampada na embalagem, principalmente se for uma marca conhecida no mercado.

Pôde-se observar que dentre as amostras analisadas na entrevista o produto de marca mais cara foi eleito como mais atraente. Indagando-as sobre os três batons que elas mais gostaram as eleitas também foram das empresas mais respeitadas no mercado, devido ao conhecimento da marca e qualidade, enquanto elas preteriram as embalagens de marcas populares e de percebida má qualidade.

Dessa maneira, observou-se que a maioria das usuárias que participaram da amostragem tem preferências por embalagens cilíndricas e arredondadas, discretas quando devem ser e chamativas quando convier. Elas preferem acabamentos que fogem do brilhante e do transparente, alegando que estes atributos simbolizam baixa qualidade e são práticas ao buscarem informações no produto, como em relação a cores e à marca.

A marca, por sua vez, ainda é um fator de grande influência na decisão de compra das entrevistadas. Pôde-se observar que algumas usuárias, mesmo não possuindo um batom de determinada marca, optaram por escolhê-la como a melhor dentre as demais. Além disso, observa-se que há dúvidas entre a preferência pela marca e pela forma do produto. Porém podemos concluir que a cor e a qualidade do batom (como beneficio) ainda são os fatores mais determinantes de compra. 


\section{Análise de mercado e Posicionamento}

A partir da Pesquisa de Marketing, foi possível realizar uma análise mercadológica (pontos fortes e fracos, oportunidades e ameaças), bem como definir os objetivos da nova marca, a fim de identificar oportunidades de atuação e definir seu posicionamento.

Os objetivos de mercado para a marca fictícia são: obtenção de conformidade de materiais e serviços; estabelecer um compromisso com os consumidores, tornando-os fiéis à marca; garantir a máxima qualidade com o menor custo; oferecer diferencial através do design e novas experiências às consumidoras no momento da compra; desenvolver produtos sustentáveis e com longo tempo de vida útil; e garantir espaço e visibilidade no mercado em que será inserida.

Posicionamento do produto é a definição clara e marcante de quais benefícios ele oferece, para quem é destinado e qual segmento de mercado pertence (ACAR FILHO, 1997). Como estratégia, a nova marca deve ser direcionada de modo a ocupar um espaço no mercado que seja favorável tanto à sua inserção, como que mantenha sua sustentabilidade dentro de seus princípios. Através da pesquisa de mercado realizada percebe-se que o posicionamento almejado colocará a lips como uma marca desejada, cujos produtos passarão a ter alto valor percebido. Ela deve posicionar-se no nicho de mercado de produtos com preço um pouco mais elevado que os populares e um pouco mais barato que as marcas mais fortes. Porém, ela estaria no mesmo patamar de popularidade das marcas concorrentes e na mesma faixa de preço.

\section{Design da Marca e Slogan}

Para CHURCHILL e PETER (2000), usar uma marca é uma maneira de distinguir bens e serviços na mente de compradores potenciais, beneficiando o consumidor. As imagens que as pessoas têm das marcas ajudam-nas a tomar decisões de compra.

O nome escolhido para a marca foi lips, vem do inglês e significa lábios. O nome foi pensado por ser curto, fácil de memorizar, ter relação direta com o produto e ser de fácil e agradável pronúncia. O formato manuscrito da fonte foi pensado como um elemento que transmite informalidade, estando inserido dentro do universo do público-alvo. O elemento gráfico da boca junto ao nome foi utilizado para enfatizar a ideia de boca e lábios no subconsciente das usuárias. Dessa forma, tanto o nome quanto a representação da boca enfatizam a ideia do batom.

O slogan tem a função de reforçar uma imagem de marca por meio da associação de valor a um nome, a uma marca (PINHO, 1996). Neste sentido, o slogan do produto - "o par perfeito para sua boca" - contribui para a redundância da mensagem da marca: a forma do produto, juntamente com o nome e a representação gráfica, transmitem a ideia de que, ao comprar um batom lips a consumidora levará para casa seu par perfeito (Figura 2).

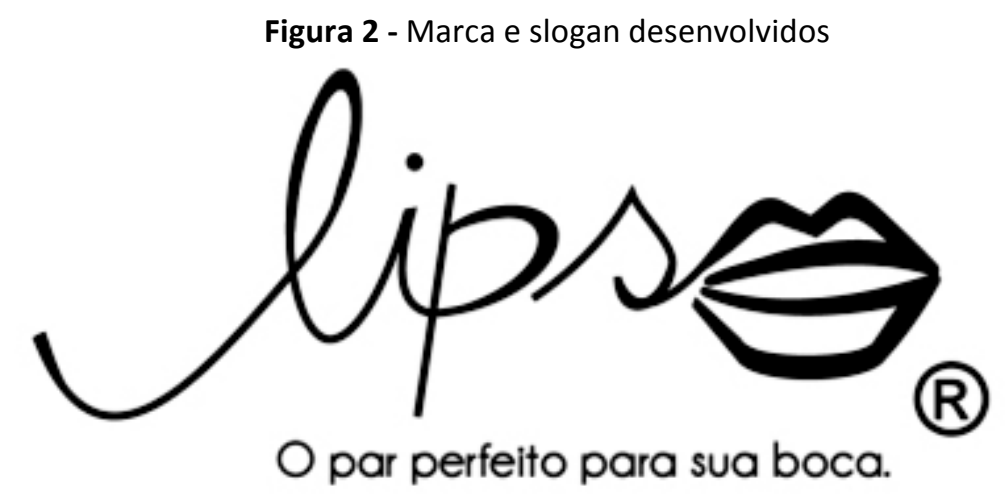




\section{Produto}

Após analisados os dados de mercado, foram elaborados vinte e dois conceitos diferentes de batom, a fim de escolher o que mais transmitisse valores como organicidade, jovialidade, feminilidade e descontração. Para isso, houve predominância das formas cilíndricas e arredondadas, bem como a utilização de cores vibrantes, que estão de acordo tanto com a Pesquisa de Mercado como com o perfil do público-alvo.

Com os conceitos gerados, retornou-se ao mercado a fim de se realizar uma pesquisa pósdesign, onde o conceito escolhido seria àquele que obtivesse a maior parte da preferência das potenciais consumidoras do produto.

O conceito escolhido foi o que possuía como princípio formal o formato de uma boca. Além disso, ele foi escolhido por quebrar paradigmas: o produto seria utilizado no sentido horizontal, diferentemente de todos os produtos existentes no mercado, que possuem sentido vertical. Dessa maneira, o conceito poderia proporcionar uma nova experiência às consumidoras, sendo este um diferencial mercadológico do produto. Dentre outros diferenciais e características inerentes a ele, destacam-se sua forma, orientação, combinação de cores aplicada e marca. Por ter o formato de uma boca, o produto atribui redundância na informação transmitida, por ser um produto essencialmente direcionado para a boca da usuária (Figura 3). Neste sentido, SCHMITT e SIMONSON (2002) afirmam que "formas tornam-se associadas a um produto ou empresa pela combinação repetida. Com a repetição ao longo do tempo, a combinação de um produto e uma forma pode tornar-se parte familiar de uma identidade".

Figura 3 - Batom lips, em forma de boca e com orientação horizontal

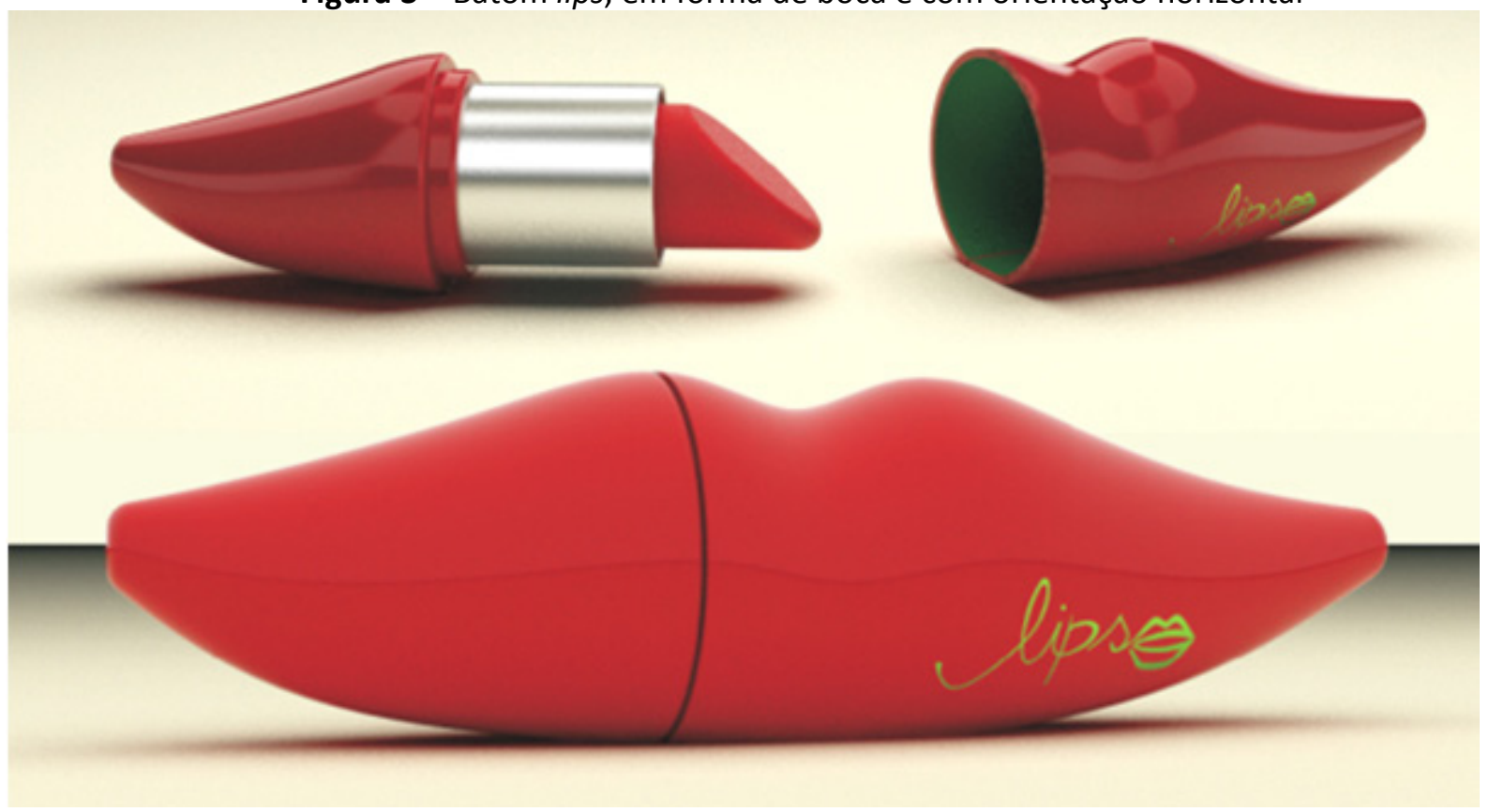

O produto, além de valor estético também possui um valor funcional agregado. Observou-se através da Pesquisa de Mercado que as usuárias olhavam a cor do batom abrindo-o. A partir deste resultado, percebeu-se a oportunidade de inovação: a embalagem proposta possuiria a sua cor externa referente à cor do batom. Assim, o produto não precisa de elementos como transparência ou adesivos, não necessitando também que a usuária abra-o para examinar a cor, pois ela já está representada em sua embalagem.

A cor também foi aplicada tanto na parte exterior da embalagem quanto em sua parte interna. Pensando no público-alvo e na Pesquisa de Mercado feita anteriormente, determinou-se que as cores seriam usadas com o princípio de harmonia e equilíbrio da combinação de cores contrastantes. Dessa maneira, a cor aplicada na parte interna da tampa da embalagem seria contrastante em relação à cor 
utilizada em sua parte externa (Figura 4).

Com relação à marca, de acordo com o observado, as usuárias gostam de marcas estampadas no exterior das embalagens. Dessa maneira, o produto possui sua marca no canto inferior direito da embalagem. Tanto a marca como o interior da tampa do produto terão cores contrastantes à cor da embalagem.

Figura 4 - Cores disponíveis para o batom lips

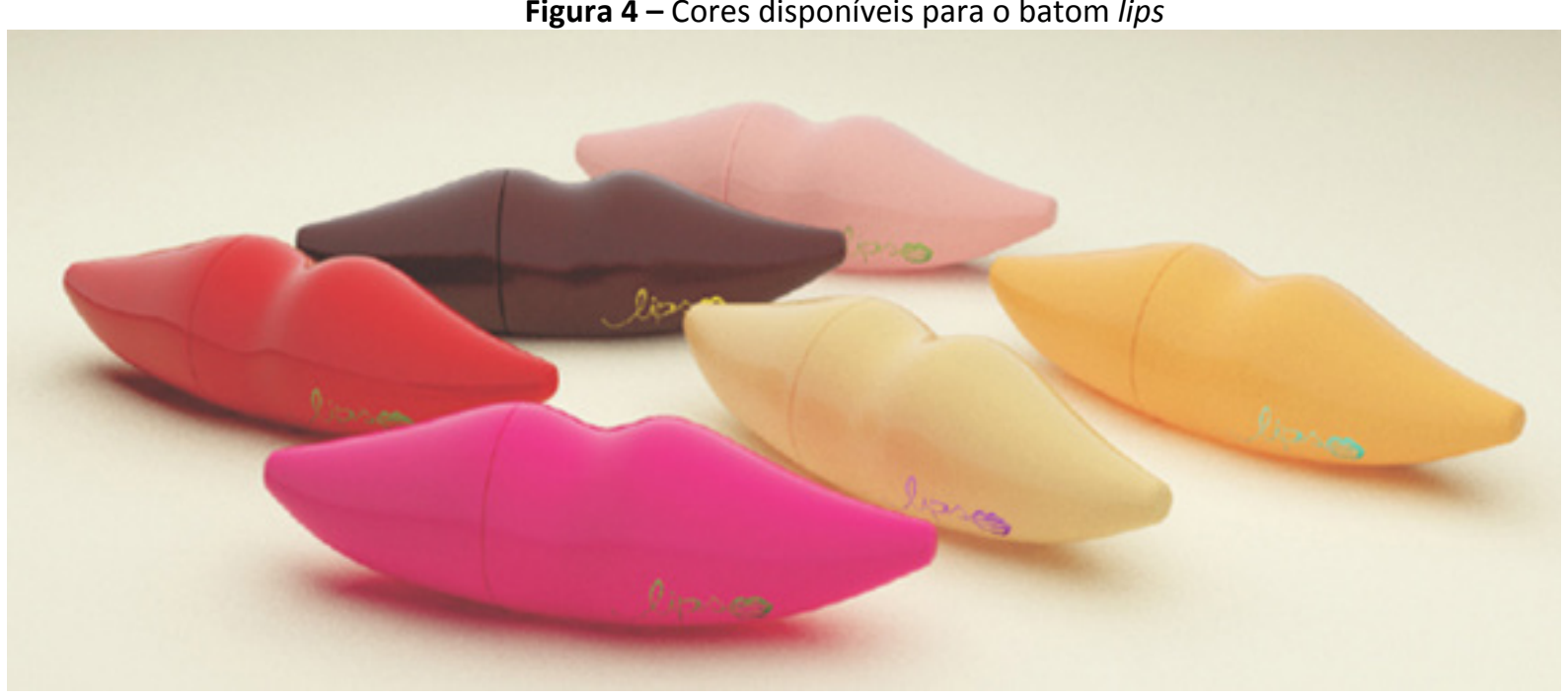

\section{Embalagem}

De acordo com MESTRINER (2002), a embalagem historicamente é uma importante ferramenta para o desenvolvimento do comércio. Proteger e viabilizar o transporte dos produtos eram as funções iniciais das embalagens antigas, porém com o passar do tempo a embalagem foi incorporando novas funções e passou a conservar, expor, vender os produtos e finalmente conquistar o consumidor por meio de seu visual atraente e comunicativo. A evolução do mercado e a maior competição entre os produtos fizeram com que a embalagem se tornasse um fator de influência na decisão de compra dos consumidores.

A embalagem foi pensada e planejada para causar uma nova experiência de compra e ter diferenciais mercadológicos, de acordo com as estratégias de marketing traçadas. Observou-se que as embalagens de batons existentes no mercado têm apenas a função de proteger e estocar o produto até o momento de sua compra. Após isso, a embalagem é descartada. A partir dessa observação, foi pensada em uma maneira de estender a vida útil da embalagem do novo produto, de maneira que ela possuísse valor agregado e possibilitasse novas utilizações para a usuária.

Após estas análises, a embalagem foi desenvolvida contendo duas partes principais: a base e a tampa. A base é constituída de papelão reciclado um pouco mais espesso que os encontrados em embalagens comuns. Isto se deve à necessidade de uma base mais firme, para que ela possa ser utilizada como porta-batom nas bolsas femininas sem que a embalagem seja facilmente danificada ou amassada com o decorrer do tempo e do uso constante. A tampa também é constituída pelo mesmo papelão da base, porém possui uma camada de papel alumínio em sua parte inferior, que confere a ela uma camada reflexiva, como um espelho, que pode ser usada pela usuária no momento de passar o batom na boca.

As duas partes, tanto a base como a tampa, são imantadas: dessa forma, a tampa pode ser facilmente encaixada e retirada da base para ser utilizada como espelho. Dessa maneira, a vida útil da embalagem será estendida (Figura 5). 
Figura 5 - Embalagem para armazenar o batomPlanejamento do Preço, Canais de Venda e Distribuição

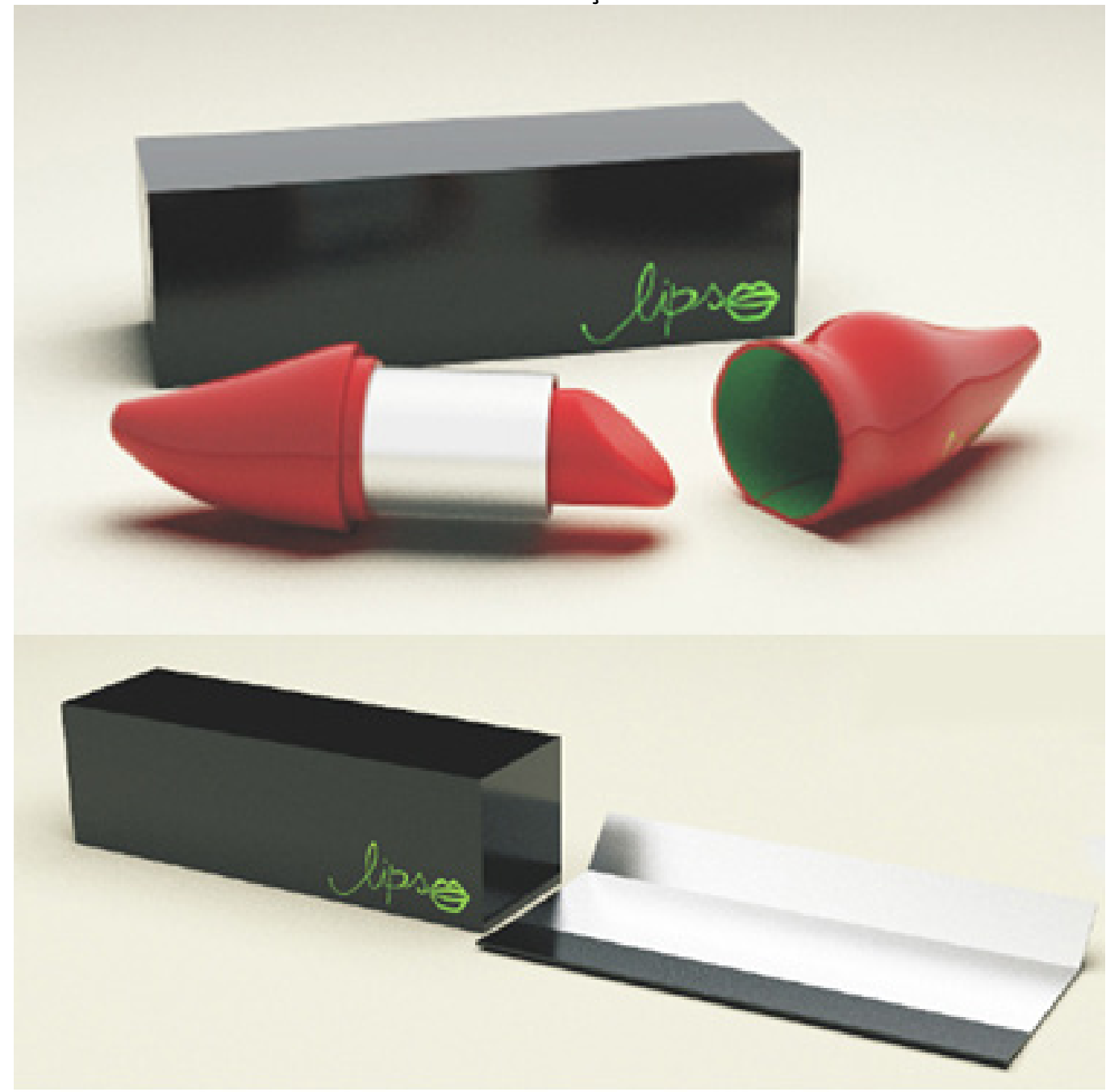

A empresa lips tem como objetivo a inserção de sua marca no mercado. Nesse sentido, a empresa deseja cobrar um preço que cubra seu custo de produção, distribuição e venda do produto, de modo a oferecer um retorno justo pelo esforço e risco. O preço foi determinado de acordo com a faixa de preços do mercado, orientados pelo preço dos principais concorrentes da marca. Além disso, os produtos teriam variações de preços e promoções de acordo com a localidade do ponto de venda, volume de vendas e pela localização dos produtos nas lojas em que será exposto e comercializado.

Analisando-se os canais de venda dos principais concorrentes do produto, pode-se perceber que são marcas que priorizam predominantemente a venda por meio de revendedoras autorizadas, revistas e catálogos da marca, lojas e filiais. Para este caso, a venda através de revistas e catálogos não seria interessante, devido à impressão de produto popular que esse canal de venda poderia transmitir. Já a venda em lojas de fábrica e filiais teria um alto custo estratégico para a empresa, que por estar entrando no mercado dificilmente teria capital suficiente para cobrir custos desse tipo.

O processo de levar mercadorias aos clientes é tradicionalmente conhecido como distribuição, começando na fábrica e terminando no Ponto de Venda (KOTLER e KELLER, 2006). Assim, a estratégia foi determinar que os batons lips fossem acondicionados em pequenas caixas (que por sua vez seriam acondicionados em caixa maiores, de transporte) e que, abertas nos pontos de venda da marca, se tornariam expositores a serem posicionados em lojas conceituadas de roupas e calçados femininos (Figura 6). Além de fazer parcerias e ligar o nome da empresa às marcas consolidadas e conceituadas, trata-se de um canal de venda de menor custo direto do que as alternativas citadas anteriormente. Em 
troca, as lojas que comercializassem os batons da marca receberiam descontos especiais nas compras em grande escala.

Figura 6 - Expositor no Ponto de Venda de uma loja de moda

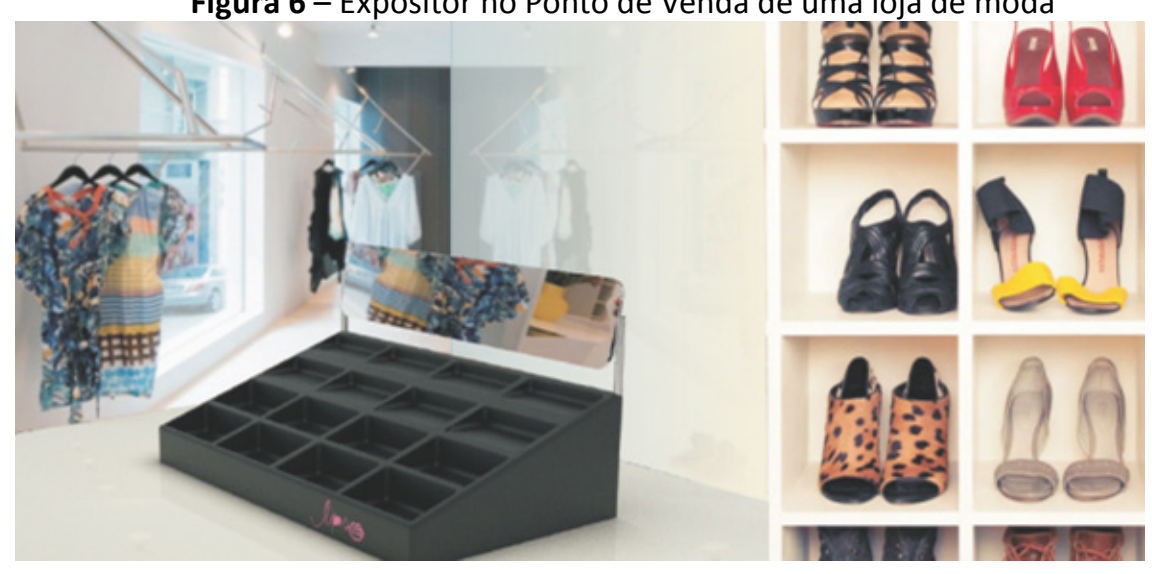

\section{Planejamento de Comunicação}

O planejamento de comunicação da marca lips tem como objetivo desenvolver uma mensagem focada no público-alvo e selecionar os canais que façam com que a marca alcance o maior número possível de potenciais usuárias, despertando sua curiosidade e desejo pelo produto, de maneira a inserir a marca no mercado.

A campanha da marca foi pensada para transmitir uma mensagem descontraída, jovem, alegre, feminina e clean. Alguns dos significados implícitos presentes na campanha são a ênfase na qualidade e sofisticação do produto e principalmente na relação da usuária com o slogan da marca: o batom seria o par perfeito das mulheres e elas se tornariam mais independentes ao adquiri-lo e utilizá-lo.

As mídias escolhidas para a veiculação da campanha publicitária foram TV, outdoors, revistas e site da internet. A propaganda televisiva foi escolhida por possuir grande visibilidade e audiência; os outdoors, por localizarem-se em áreas comerciais e de grande circulação de pessoas, além de comunicar em quais lojas da cidade o produto poderia ser encontrado; as revistas foram escolhidas como uma mídia impressa focada no público-alvo, como propagandas em revistas femininas de moda e afins; a internet foi escolhida por ser um meio que demanda investimento relativamente baixo e permite rápida propagação da informação de maneira fácil e acessível a uma grande número de pessoas.

A partir da definição de que mensagem seria transmitida às consumidoras e das mídias em que ela seria veiculada, partiu-se para elaboração da mídia básica, aquela que definiria o estilo gráfico das outras mídias escolhidas; nesse caso, optou-se pela TV como mídia básica. A peça explorou um fundo limpo e neutro na cor branca, que ressaltasse o aspecto clean da peça e destacasse o batom e a imagem das modelos usando o produto. As modelos escolhidas foram jovens, sendo uma morena, uma loira e uma ruiva, de modo que o produto se adapta aos diferentes tipos de consumidoras. A partir da mídia básica, se desenvolveram as mídias de apoio, no caso outdoors, revista feminina e site (Figura 7), além de canais de vídeo na internet, como forma de difundir o produto em diversas frentes. 


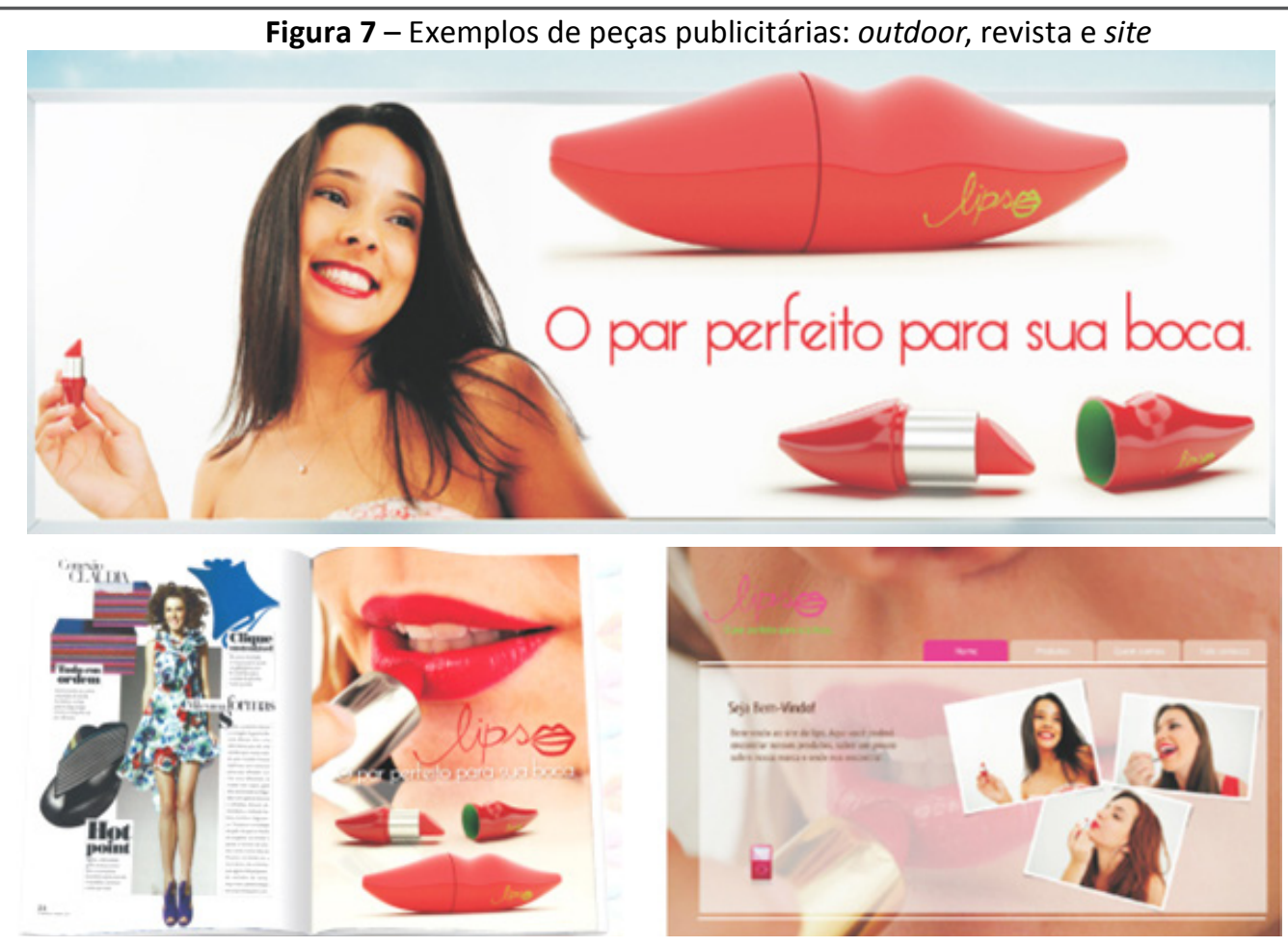

\section{Conclusões}

A pesquisa de mercado proporcionou base empírica para a posterior elaboração do planejamento das estratégias de marketing, guiando a marca para um melhor entendimento de como se comporta o público-alvo em relação ao produto estudado, quais suas preferências e o que eles priorizam. É uma ferramenta que permite compreensão dos fatores importantes e decisivos no momento da compra, de como o produto é percebido pelo mercado e a maneira como os consumidores se comportam diante dele. Foi possível conhecer numa fase pré-design as preferências e hábitos das usuárias em relação ao mercado de batons, de modo a embasar o planejamento e direcionar as decisões posteriores. As potenciais consumidoras tiveram papel fundamental e ativo nas decisões de Marketing e Design, tendo suas opiniões levadas em consideração desde o design do produto e da marca até o formato das peças publicitárias desenvolvidas.

O planejamento de marketing é importante no que diz respeito à definição de estratégias de branding, como no caso apresentado para lançamento de uma nova marca no mercado, mesmo se tratando de um trabalho em nível acadêmico, servindo também de guia para elaboração das peças de design no âmbito de todo composto mercadológico.

Nesse sentido, o Design assume papel fundamental como expressão das intenções e estratégias da empresa, reforçando a coesão da identidade corporativa e fortalecendo a marca. Além disso, o design caracteriza-se como elemento inovador, trazendo ao mercado novos produtos, embalagens e modos de comunicação com o consumidor. Como resultado, o design do produto, por ter sido desenvolvido como trabalho acadêmico, por se caracterizar como inovação e para fins de proteção dos direitos autorais, já foi registrado junto ao INPI.

Por fim, observa-se que o planejamento prévio, seja ele qual for, é de grande importância para minimizar os riscos e garantir que as decisões escolhidas são as melhores a serem tomadas. Planejamento, pesquisas e análises constituem o fundamento para se conhecer o que se projetar, proporcionando uma base de informações que atuam como referência e o guia para o projeto de design. 
Torres, Pablo Marcel de Arruda; Dantas, Laíla Alves Marinho

\section{Referências}

ACAR FILHO, N. Marketing no projeto e desenvolvimento de novos produtos: o papel do designer. São Paulo: FIESP/CIESP-Detec, 1997.

BORJA DE MOZOTA, B. Design and Competitive Edge: A Model for Design Management Excellence in European SMEs. DMI Academic Review, 2002.

BORJA DE MOZOTA, B. Gestão do Design. Porto Alegre: Bookman, 2011.

CHURCHILL, G. A.; PETER, J. P. Marketing: criando valor para os clientes. 2a ed. São Paulo: Saraiva, 2000.

DE MORAES, D. Metaprojeto: o design do design. São Paulo: Blucher, 2010.

DEMARCHI, A. P. P.; FORNASIER, C. B. R.; MARTINS, R. F. F. A Gestão de Design humanizada pelo Design thinking a partir de relações conceituais. In: Projética Revista Científica de Design. Londrina: Universidade Estadual de Londrina, v.2, n.1, Junho 2011.

DICKINSON, P.; SVENSEN, N. Beautiful corporations: corporate style in action. Londres: Pearson, 2000.

GILLESPIE, B. Strategic Design Management and the Role of Consulting. 2002. Disponível em: $<$ http://www.designingbusiness.com/BrianG_SDM_ResearchReport.pdf>. Acesso em: 06 jun. 2012.

KOTLER, P.; KELLER, K. Administração de Marketing. 12a ed. São Paulo: Pearson Prentice Hall, 2006.

LÖBACH, B. Design industrial: Bases para a configuração dos produtos industriais. São Paulo: Editora Blucher, 2001.

MAGALHÃES, C. Design Estratégico: integração e ação do Design Industrial dentro das empresas. SENAI/DN-SENAI/CETIQT-CNPq -IBICT - PADCT - TIB, 1997.

MESTRINER, F. Design de Embalagem. São Paulo: Pearson Makron Books, 2002.

PINHO, J. B. O Poder das Marcas. São Paulo: Summus, 1996.

SAMARA, B. S.; BARROS, J. C. Pesquisa de Marketing: Conceitos e metodologia. 4a ed. São Paulo: Pearson Prentice Hall, 2007.

SCHMITT, B.; SIMONSON, A. A Estética do Marketing. Como criar e administrar sua marca, imagem e identidade. São Paulo: Nobel, 2002.

YAMAMOTO, M.; LAMBERT, D. The Impact of Product Aesthetics on the Evaluation of Industrial Products. In: Journal of Product Innovation Management. Vol. 11, Issue 4, Setembro 1994. 